\title{
Pengembangan Job Sheet Pratikum Elektronika Daya
}

\author{
Sislia Laras Putri ${ }^{1^{*}}$ \\ ${ }^{1}$ Jurusan Teknik Elektro, Fakultas Teknik, Universitas Negeri Padang \\ "e-mail: sislialaras@gmail.com
}

(Diajukan: 08Juli 2021, direvisi: 26 Juli 2021, disetujui: 29 Juli 2021)

\begin{abstract}
Abstrak
Penelitian ini membahas tentang pengembangan job sheet pembelajaran Elektronika Daya. Job sheet pembelajaran membantu mahasiswa untuk belajar secara mandiri. Oleh karena itu, job sheet merupakan salah satu sarana pembelajaran yang sangat efektif yang berisi infrormasi/petunjuk untuk menyelesaikan pratikum dan mampu mengoptimalkan belajar secara mandiri bagi mahasiswa. Tujuan penelitian untuk menghasilkan job sheet Elektronika Daya yang valid, praktis, dan efektif. Tahap penelitian mengacu pada tahap metode Research \& Development (R\&D). Penelitian ini menggunakan model 4-D, (1) Pendefenisian (Define), (2) Perancangan (Design), (3) Pengembangan (Development), dan (4) Penyebaran (Disseminate). Teknik analisis data dalam penelitian ini adalah deskriptif kuantitatif. Hasil penelitian dari pengembangan job sheet ini dinyatakan dengan kategori valid dengan memperoleh tingkat pencapaian $91.25 \%$. Respon Dosen terhadap kepraktisan job sheet yaitu $98.18 \%$ dengan kategori sangat praktis sedangkan respon mahasiswa yaitu sebesar $90.95 \%$. Secara keseluruhan rata-rata hasil belajar setelah pratikum menggunakan job sheet sebesar $100 \%$. Berdasarkan hasil tersebut job sheet dinyatakan valid, praktis, dan efektif digunakan pada pratikum elektronika daya.
\end{abstract}

Kata Kunci: job sheet, valid, praktis, efektif.

\begin{abstract}
This study discusses the development of the Power Electronics learning worksheet. Learning job sheets help students to study independently. Therefore, the job sheet is one of the most effective learning tools that contain information/instructions to complete the practicum and can optimize independent learning for students. The research objective is to produce a valid, practical, and effective Power Electronics worksheet. The research stage refers to the Research \& Development (R\&D) method stage. This study uses a 4-D model, (1) Definition, (2) Design, (3) Development, and (4) Disseminate. The data analysis technique in this research is descriptive quantitative. The results of the research from the development of this worksheet are stated in a valid category by obtaining an achievement rate of $91.25 \%$. The lecturer's response to the practicality of the job sheet is $98.18 \%$ in the very practical category, while the student's response is $90.95 \%$. Overall, the average learning outcome after practicum using the job sheet is $100 \%$. Based on these results, the job sheet is declared valid, practical, and effectively used in power electronics practicum.
\end{abstract}

Keywords: job sheet, valid, practical, effective. 


\section{PENDAHULUAN}

Pendidikan berfungsi untuk meningkatkan potensi diri pada manusia untuk keberhasilan menjalani kehidupan serta mampu mewujudkan cita-cita bangsa Indonesia, yaitu mencerdaskan kehidupan bangsa [1]. Hal ini sesuai dengan tujuan dari bangsa Indonesia yang termuat dalam pembukaaan UUD 1945, yaitu mencerdaskan kehidupan bangsa [2]. Oleh karena itu, perlu dilakukan usaha terus-menerus agar pendidikan berkualitas bagi manusia sehingga menghasilkan Sumber Daya Manusia (SDM) yang memiliki keterampilan, bermutu, dan professional sehingga mencapai sesuai dengan tujuan. Salah satu cara untuk mewujudkan Sumber Daya Manusia (SDM) yang berkualitas itu berawal dari bidang pendidikan. Kualitas pendidikan harus ditingkatkan melalui strategi dan pendekatan pembelajaran yang efektif. Adapun lembaga pendidikan yang menunjang untuk mewujudkan tercapainya tujuan dari bangsa Indonesia yang ingin mencerdaskan kehiduoan bangsa adalah perguruan tinggi [3]. Perguruan tinggi merupakan institusi tertinggi dalam dunia pendidikan yang menjadi wadah untuk mempersiapkan peserta didik agar memiliki kemampuan akademis dan profesional yang dapat menerapkan, mengembangkan dan menciptakan ilmu pengetahuan dan teknologi yang ada. Perguruan Tinggi berorientasi untuk menciptakan lulusan bagi mahasiswa yang berkualitas yang memiliki kompetisi yang mudah diterima pada dunia kerja/industry sesuai dengan bidangnya masing-masing [4].

Univeristas Negeri Padang memiliki beberapa fakultas, salah satunya adalah fakultas teknik. Fakultas teknik juga ada beberapa jurusan diantaranya jurusan teknik elektro. Berbagai mata kuliah disajikan dalam jurusan teknik elektro salah satunya mata kuliah praktik elektronika daya. Mata kuliah praktik elektronika daya salah satu mata kuliah wajib yang harus di ambil mahasiswa S1 Teknik Elektro. Salah satu mata kuliah yang memerlukan penyempurnaan media pembelajaran Job sheet adalah mata kuliah Praktek Elektronika Daya di Jurusan Teknik Elektro Fakultas Teknik Universitas Negeri Padang yang merupakan mata kuliah wajib bagi mahasiswa Strata 1 (S1) Pendidikan Teknik Elektro Jurusan Teknik Elektro. Pada Rencana Perkuliahan Elektronika daya mencakup beberapa materi, antara lain ; penyearah setengah gelombang dan gelombang penuh 1 fasa, penyearah setengah gelombang dan gelombang penuh 3 fasa, penyearah terkendali semi converter dan full converter 1 fasa, penyearah terkendali semi converter dan full converter 3 fasa, DC-DC converter (Buck, Boost, Buck-Boost, Cuk), Inverter 1 fasa dan 3 fasa. Mata kuliah ini selain harus memahami teorinya, juga memiliki pembelajaran praktik. Hal ini membutuhkan pemahamanan dan keterampilan masing-masing mahasiswa [5].

Berdasarkan hasil observasi yang telah dilakukan, kurangnya media yang praktis dan inovatif serta tampilan dari job sheet yang lama masih sangat sederhana dan kurang menarik. Sehingga menjadi penyebab rendahnya minat belajar mahasiswa dan kurang memahami materi dalam melaksakan proses pembelajaran. Akibatnya materi yang disampaikan dosen tidak dipahami maksimal oleh mahasiswa. Apalagi pada saat sekarang ini mahasiswa dituntut mampu belajar mandiri baik proses pembelajaran secara tatap langsung maupun secara daring [6]. Dari permasalahan tersebut dapat disimpulkan bahwa cara untuk mengatasi masalah ini adalah dengan pengembangan job sheet. Dengan adanya job sheet mahasiswa bisa memahami materi pelajaran di job sheet 
dan bisa melaksanakan proses pembelajaran secara mandiri sesuai dengan perintah job sheet dan dosen yang mengajar. Keunggulan dari media pembelajaran job sheet untuk pratikum elektronika daya yang akan dikembangkan yaitu job sheet yang dikembangkan sangat praktis dan job sheet dapat digunakan disaat proses pembelajaran tatap muka maupun pembelajaran daring serta di dalam job sheet juga ditambahkan ilustrasi gambar percobaan yang berfungsi untuk memudahkan memahami suatu keterangan atau penjelasan [7]. Pembeda antara job sheet yang dikembangkan dalam penelitian ini dengan penelitian sebelumnya tersebut ada pada perbedaan kompetisi dan perbedaan pendekatan pengembangan. Hal tersebut dikarenakan adanya perbedaan kebutuhan pengembangan sesuai karakteristik kompetisi pada job sheet yang dikembangkan. Dengan adanya job sheet maka kesalahan di dalam pratik dapat berkurang karena job sheet berisi panduan daan tata cara dalam penyelesaian pekerjaan [8].

Menurut peneliti sebelumnya yaitu [9] mengungkapkan bahwa munculnya mata pelajaran baru tentunya mengakibatkan berbagai macam persoalan yang berhubungan dengan kesiapan pendidik dalam mengajar. Belum adanya job sheet untuk pratikum membuat peserta didik tidak memahami dalam pelaksanaan proses pembelajaran. Solusi yang diberikan peneliti tersebut dengan mengembangkan job sheet mata pelajaran instalasi motor listrik dapat dilihat dari hasil penelitiannya uji validitas dengan nilai 0,87 kategori valid, uji praktikalitas oleh peserta didik sebesar $93 \%$ dan pendidik sebesar $92 \%$ dan uji efektifitas sebesar $88 \%$. Berdasarkan pada uraian diatas, maka dilakukan upaya penilaian validitas, praktikalitas dan efektifitas job sheet Pratikum Elektronika Daya. Penelitian ini bertujuan untuk menghasilkan job sheet Elektronika Daya yang valid, praktis, dan efektif. Penelitian ini diharapkan mampu untuk mengoptimalkan proses pembelajaran secara mandiri dan meningkatkan kemampuan bagi mahasiswa. Sesuai dengan penjelasan yang telah diuraikan maka kelengkapan job sheet sangat berpengaruh pada minat dan hasil belajar mahasiswa.

\section{METODE}

Penelitian ini dilaksanakan dengan cara pengujian dan mengambil data di Jurusan Teknik Elektro, Fakultas Teknik, Universitas Negeri Padang. Jenis penelitian yang diterapkan yaitu; Recearch \& Development (R\&D) dengan menggunakan model pengembangan 4-D. Alur penelitian yang diterapkan yaitu; (1) Pendefenisian (Define); (2) Perancangan (Design); (3) Pengembangan (Development); dan (4) Penyebaran (Dessimante) [10]. Penelitian ini dapat dilihat pada gambar dibawah ini. Tahap pertama dalam penelitian ini yaitu; (1) analisis ujung depan; (2) analisis peserta didik; (3) analisis konsep; (4) analisis tugas; (5) perumusan tujuan pembelajaran [11]. Tahap pendefenisian bertujuan menetapkan materi pembelajaran sesuai dengan tujuan penelitian. Tahap kedua yaitu; (1) penyusunan garis besar isi job sheet; (2) mendesain isi pembelajaran pada job sheet; (3) pemilihan format; (4) penulisan naskah job sheet. Tujuan dari tahap perancangan untuk merancang job sheet pratikum elektronika daya yang akan dikembangkan. Dimana produk awal harus sesuai standar kelayakan agar mudah dipahami materi untuk melaksanakan praktik. 


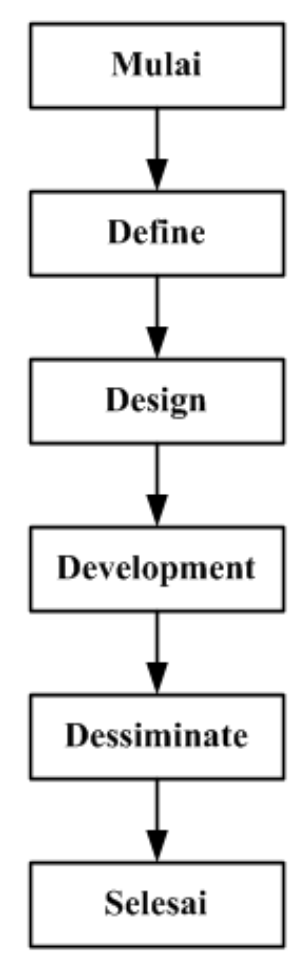

Gambar 1 langkah-langkah Metode Research and Development

Tahap ketiga yakni; (1) validasi job sheet oleh validator; (2) uji coba lapangan; (3) uji praktikalitas job sheet; (4) uji efektifitas job sheet. Tujuan akhir dari tahap ini yaitu untuk menghasilkan produk berupa job sheet pratikum elektronika daya setelah melalui revisi berdasarkan masukan dan saran yang diberikan validator terhadap produk yang dikembangkan oleh peneliti. Tahap keempat atau tahap terakhir yaitu penyebaran job sheet yang telah dilakukan uji pada produk yang dikembangkan dan dinyatakan valid, praktis, dan efektif pada Jurusan Teknik Elektro Fakultas Teknik Universitas Negeri Padang. Tahap ini adalah tahap penyebaran produk yang telah dikembangkan pada skala kecil, misalnya mencakup satu kelas.Analisis data pada penelitian ini menggunakan teknik analisis deskriptif yang memaparkan hasil pembuatan produk berupa Job sheet pembelajaran pada mata kuliah Elektronika daya [12]. Analisis ini dimaksud untuk menggambarkan karakteristik data pada masing-masing variable. Analisis data Validitas, praktikalitas dan efektifitas menggunakan skala likert yaitu dapat dilihat pada tabel 1 [13]

Tabel 1 indikator Variabel Skala Likert [13]

\begin{tabular}{ccc}
\hline No. & Indikator variabel & Skor \\
\hline 1 & Tidak Baik & 1 \\
2 & Kurang Baik & 2 \\
3 & Cukup Baik & 3 \\
4 & Baik & 4 \\
5 & Sangat Baik & 5 \\
\hline
\end{tabular}

A. Validasi Produk

Angket validitas digunakan untuk mengukur tingkat kevalidan job sheet yang telah dibuat. Angket validitas ini terdiri dari beberapa aspek penilaian, yang terdiri dari syarat didaktik, syarat kontruksi dan syarat teknis [14]. Indikator penilaian 
diantaranya komponen isi dan tujuan, intruksional serta teknis. Sedangkan validator terdiri dari ahli materi dan ahli media. Hasil skor yang didapatkan selanjutnya dijumlahkan dan dianalisis menggunakan rumus (1). Berdasarkan nilai validitas yang telah diperoleh, lalu dapat dikategorikan tingkat pencapaiannya sesuai dengan tabel $2[15]$.

$$
\text { Nilai Validitas }=\frac{\text { Jumlah skor yang diperoleh }}{\text { Jumlah skor maksimum }} \times 100 \%
$$

Tabel 2 Kategori Kevalidan Job sheet [13]

\begin{tabular}{ccc}
\hline No & Tingkat Pencapaian (\%) & Kategori \\
\hline 1 & $90-100$ & Sangat valid \\
2 & $80-89$ & Valid \\
3 & $65-79$ & Cukup Valid \\
4 & $55-64$ & Kurang Valid \\
5 & $\leq 54$ & Sangat Tidak Valid \\
\hline
\end{tabular}

B. Uji Coba Produk

Setelah job sheet pembelajaran divalidasi dan diperbaiki sesuai saran dari dosen ahli, maka job sheet dapat diuji cobakan untuk melihat respond an daya tarik dari job sheet tersebut. Uji praktikalitas dilakukan oleh dosen yang pernah mengajar mata kuliah Elektronika daya dan mahasiswa sebagai pengguna job sheet [16]. Kepraktisan job sheet merupakan data praktikalitas yang didapatkan dengan menganalisis angket praktikalitas yang telah diisi oleh responden. Data Praktikalitas job sheet dianalisis dengan persentase (\%), menggunakan rumus (2). Berdasarkan hasil nilai responden yang diperoleh, kemudian dilakukan pengelompokkan sesuai kategori dengan tingkat pencapaaian seperti pada tabel 2 [17].

$$
\text { Nilai praktikalitas }=\frac{\text { Jumlah skor yang diperoleh }}{\text { Jumlah skor maksimum }} \times 100 \%
$$

C. Analisis Efektivitas

Analisis efektivitas job sheet dilakukan untuk mengetahui kelayakan job sheet yang dikembangkan . Data efektivitas didapatkan setelah hasil belajar peserta didik diperoleh melalui penilaian kinerja menggunakan kinerja rubric. Suatu kelas dikatakan tuntas belajar (proses pembelajaran) atau disebut juga ketuntasan klasikal jika didalam kelas tersebut terdapat $\geq 85 \%$ siswa yang tuntas belajarnya. Untuk mengetahui presentasi ketuntasan klasikal siswa dapat dihitung menggunakan rumus (3) [18]:

$$
\mathrm{PK}=\frac{J T}{J S} \times 100 \%
$$

Keterangan :

$\mathrm{PK}=$ presentase Kelulusan

$\mathrm{JT}=$ Jumlah siswa yang lulus

$\mathrm{JS}=$ Jumlah siswa peserta tes. 


\section{HASIL DAN PEMBAHASAN}

Hasil penelitian yang telah dilakukan adalah sumber pembelajaran berupa $J o b$ sheet. Penelitian yang dilakukan bertujuan untuk menghasilkan job sheet sebagai sumber belajar bagi mahasiswa yang melakukan pratik dengan memenuhi kriteria valid, praktis dan efektif. Validasi job sheet pembelajaran diperoleh dari hasil penilaian dari tim validator untuk job sheet pembelajaran tersebut. Hasil penilaian tersebut didapatkan melalui analisis lembar validasi job sheet yang telah diisi sebelumnya oleh tim validator. Adapun tim validator terdiri dari dua orang yang merupakan dosen teknik elektro yang ahli dalam bidangnya. Adapun hasil validasi dari job sheet pembelajaran tersebut dapatdilihat pada Tabel 3.

Tabel 3 Hasil Validasi Job sheet

\begin{tabular}{cccc}
\hline No & Validator & Tingkat Pencapaian & Kategori \\
\hline 1 & Validator 1 & $90 \%$ & Sangat Valid \\
2 & Validator 2 & $92,5 \%$ & Sangat Valid \\
\hline
\end{tabular}

Validator 1 memberikan nilai 90\% dengan kategori sangat valid, sedangkan validator 2 memberikan nilai 92,5\% dengan kategori sangat valid. Sehingga didapatkan rata-rata dari hasil validasi yaitu dengan nilai $91,25 \%$ yang termasuk kedalam kategori sangat valid. Selain dalam bentuk tabel hasil validasi oleh dua validator disajikan juga data dalam bentuk grafik untuk melihat indikator penilaian dari masingmasing validator.

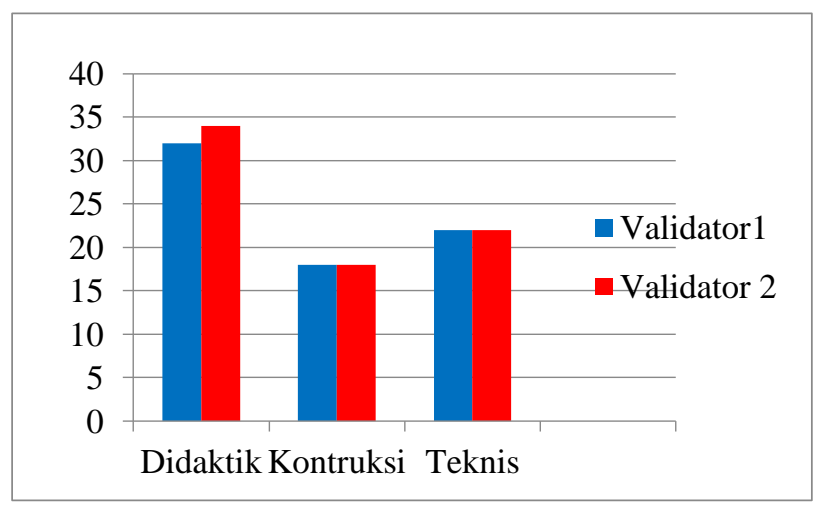

Gambar 2 Grafik Indikator Validitas dari Validator

Setelah mendapatkan nilai yang valid, job sheet diperbaiki sesuai dengan saran dari validator dan selanjutnya dilakukan uji praktikalitas untuk mengetahui daya tarik dari job sheet pembelajaran. Uji praktikalitas dilakukan oleh dosen yang pernah mengajar mata kuliah elektronika daya dan mahasiswa sebagai pengguna job sheet. Hasil dari uji praktikalitas dapat dilihat pada Tabel 4. Dari tabel 4 dapat diketahui bahwa hasil uji praktikalitas oleh dosen didapatkan nilai 98,18\% dengan kategori sangatpraktis. sedangkan hasil uji praktikalitas oleh mahasiswa sebagai pengguna job sheet didapat dengan nilai rata-rata $83,73 \%$ dengan kategori sangat praktis. 
Tabel 4 Hasil Praktikalitas Job sheet

\begin{tabular}{|c|c|c|c|}
\hline No & Responden & Tingkat Pencapaian & Kategori \\
\hline 1 & Dosen & $98,18 \%$ & Sangat praktis \\
\hline 2 & Mahasiswa & $83,73 \%$ & Sangat praktis \\
\hline & Rata-rata & $90,95 \%$ & Sangat praktis \\
\hline
\end{tabular}

Sehingga didapat nilai rata-rata 90,95\% dengan kategori sangat praktis. Selain dalam bentuk tabel hasil praktikalitas oleh responden disajikan juga data dalam bentuk grafik untuk melihat penilaian responden dari masing-masing indikator pada angket praktikalitas.

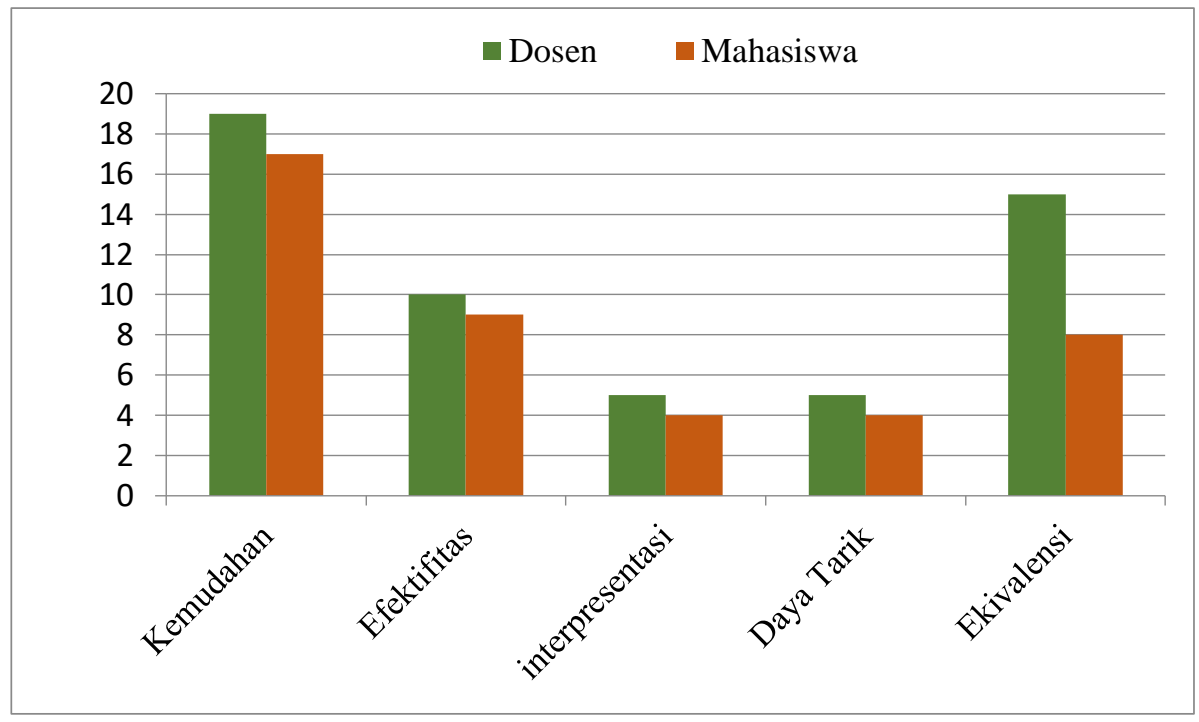

Gambar 3 Grafik Indikator Praktikalitas dari Responden

Setelah dilakukan uji validasi dan praktikalitas, maka dilanjutkan dengan uji efektivitas kepada mahasiswa. Uji efektivitas job sheet dilakukan dengan rubric penilaian unjuk kerja siswa selama menggunakan job sheet. Standar ketuntasan belajar yang diperoleh peserta didik setiap individuanya sebesar $\geq 75 \%$. Berdasarkan hasil penilaian ketuntasan individu bahwa sebanyak 4 peserta didik dari 4 peserta didik tuntas dalam proses belajar, job sheet dapat dikatakan efektif jika peserta didik sudah memenuhi kriteria ketuntasan belajar yang dikemukakan oleh depdikbud yaitu $: \geq 85 \%$. Dari penelitian ini hasil yang diperoleh pada ketuntasan individu siswa sebesar $100 \%$ dari 4 peserta didik telah memenuhi ketuntasan belajar. Oleh karena itu dapat dikatakan bahwa job sheet yang digunakan sudah efektif.

\section{KESIMPULAN DAN SARAN}

Berdasarkan hasil penelitian dan pembahasan yang telah dilakukan dapat disimpulkan bahwa : (1) Job sheet praktik Elektronika daya untuk jurusan teknik elektro Universitas Negeri Padang sudah dapat dinyatakan valid berdasarkan uji validitas oleh tim validator dengan rata-rata 91,25\%; (2) Hasil kepraktikalitas job sheet sudah dapat dinyatakan praktis berdasarkan uji praktikalitas oleh Dosen dan Mahasiswa, praktikaliras Dosen sebesar $98.18 \%$ dengan kategori sangat praktis dan hasil praktikalitas oleh mahasiswa 83,73\% dengan kategori sangat praktis; (3) job sheet dapat dikatakan efektif berdasarkan hasil uji efektivitas yang dilakukan dari lembar penilaian 
kinerja yaitu dengan memenuhi ketuntasan klasikal dengan ketuntasan klasikal mahasiswa dengan rata - rata $100 \%$.

\section{REFERENSI}

[1] Aswari, M. Yuhendri, and T. P. Yanto, Teknik elektronika daya. Malng: CV IDRH, 2020.

[2] A. Arsyad, Media pembelajaran. Jakarta: PT. Raja grafindo persada, 2014.

[3] S. Azwar, Reliabilitas dan validitas. Yogyakarta: Pustaka belajar, 2015.

[4] O. P. Azmi, "Pengembangan job sheet sebagai media pembelajaran pada mata kuliah pratikum elektronika analog dan digital di Jurusan Teknik Elektro FT UNP," Padang, 2018.

[5] C. Dewi, D. T. P. Yanto, and Hastuti, "The development of power electronic training kits for electrical engineering student: a validity test analysis," $J$. Pendidik. Teknol. Kejuru., vol. 3, no. 2, 2020.

[6] D. T. P. Yanto, "Praktikalitas nedia pembelajaran interaktif pada proses pembelajaran rangkaian listrik," INVOTEK J. Inov. Vokasional dan Teknol., vol. 19, no. 1, pp. 75-82, 2019.

[7] Depdiknas, Panduan pengembangan bahan ajar. Jakarta: Departemen Pendidikan Nasional, 2008.

[8] D. Mahadiraja and Syamsuarnis, "Pengembangan modul Pembelajaran Berbasis Daring pada Mata Pelajaran Instalasi Penerangan Listrik Kelas XI Teknik Instalasi Tenaga Listrik T.P.2019/2020 di SMK Negeri 1 Pariaman," JTEV (Jurnal Tek. Elektro dan Vokasional), vol. 6, no. 1, pp. 77-82, 2020.

[9] M. Fransisca, "Pengujian Validitas, Praktikalitas, dan Efektivitas Media Elearning di sekolah menengah kejuruan," VOLT J. Ilm. Pendidik. Tek. elektro, vol. 2, no. 17-22, 2017.

[10] L. Hirzan and M. Yuhendri, "Pengembanga E-Modul Mata Pelajaran Instalasi Penerangan Listrik untuk Pembelajaran Daring," J. Pendidik. Tek. elektro, vol. 1, no. 1, pp. 142-146, 2020.

[11] Y. Nurhidayah, "Pengembangan Bahan Ajar converter Buck pada mata kuliah pratikum elektronika daya di jurusan Teknik Elektro Fakultas Teknik Universitas Negeri Malang," Malang, 2013.

[12] R. Afrianto, "Pengembangan job sheet praktik pada mata pelajaran pekerjaan dasar elektromekanik kelas X teknik ketenagalistrikan di SMKN 2 lubuk basung," Padang, 2019.

[13] R. Kurniawan and H. Effendi, "Pengembangan job sheet Mata Pelajaran Instalasi Motor Listrik untuk kelas XI TIT," JTEV (Jurnal Tek. Elektro dan Vokasional), vol. 6, no. 1, pp. 35-41, 2020.

[14] R. Fadli and M. Yuhendri, "Pengembangan job sheet Trainer Motor Listrik di sekolah Menengah Kejuruan," J. Pendidik. Tek. elektro, vol. 1, no. 1, pp. 38-42, 2020. 
[15] R. H. Harahap and M. Muskhir, "Pengembangan job sheet Praktik Pekerjaan dasar Elektromekanik di Sekolah Menengah Kejuruan," J. Pendidik. Tek. elektro, vol. 1, no. 1, pp. 104-108, 2020.

[16] Sugiyono, Metode Penelitian Pendidikan Pendekatan Kuantitatif, Kualitatif dan $R \& D$. Bandung: alfabeta, 2014.

[17] Sl. Riyadi, Konverter statis: chopper dan PWM Rectifier serta Aplikasinya. Semarang: Universitas Katolik Soegijapranata, 2018.

[18] T. Anisa, "Pengembangan Job sheet mata pelajaran pekerjaan dasar elektro mekanik kelas X di SMK Negeri 1 Padang," Padang. 
Halaman ini sengaja dikosongkan 